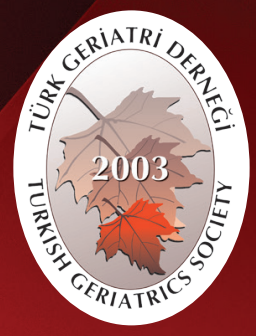

Turkish Journal of Geriatrics

DOI: 10.31086/tigeri.2018240426

2018:21 (2):252-262

- Dilek ÜNAL ${ }^{1}$

- Ijpek ÖZYAYLALI2

- İsmail Hakan KULAÇOĞLU³

RESEARCH

\title{
SAFETY OF OUTPATIENT HERNIORRHAPHY IN THE GERIATRIC PATIENT: A RETROSPECTIVE COMPARATIVE STUDY
}

\section{Abstract}

Materials and Method: A retrospective medical record review of geriatric patients aged $\geq 65$ years (Group $G, n=185$ ) who had undergone outpatient inguinal hernia repair under local infiltration anesthesia (LIA) and sedation was conducted. Their data were compared with those of a group of nongeriatric patients aged 18-64 years (Group C, n=185). Patient selection, anesthetic and surgical care, and discharge criteria were protocol-based. Safety was evaluated in terms of incidence of adverse events, discharge delay, unanticipated admission and readmission and time to discharge.

Results: Results for the Groups $G$ and $C$ were age $73.2 \pm 7.1$ vs. $43.9 \pm 12.3$ years, number of high-risk patients with American Society of Anesthesiologists classification (ASA) III ( $\mathrm{n}=55$ [30\%] vs. $5[3 \%])$, ASA IV ( $n=4$ [2\%] vs. 1 [0.5\%]), minimal sedation was used in 158 vs. 163 patients, midazolam dose $2.7 \pm 1.1$ vs. $4.6 \pm 1.7 \mathrm{mg}$, fentanyl dose $63.4 \pm 28.6$ vs. $88.1 \pm 32.4 \mu \mathrm{g}$, lidocaine dose $246.6 \pm 59.9$ vs. $198.6 \pm 69.8 \mathrm{mg}$, and bupivacaine dose $39 \pm 9.5$ vs. $47.7 \pm 10.7$ $\mathrm{mg}$, respectively. Times to discharge were $102 \pm 19 \mathrm{~min}$ and $91.2 \pm 22.5 \mathrm{~min}$ in Groups $\mathrm{G}$ and $C$, respectively. Groups were similar regarding the rate of intraoperative and postoperative adverse events, except for ecchymosis ( $n=2$ in Group $G$ vs. $n=10$ in Group C) and the rates of discharge delay, unanticipated admission, and readmission.

Conclusion: Outpatient inguinal herniorrhaphy under LIA and sedation in geriatric patients is as safe as in the nongeriatric patients, provided that protocol-based preoperative evaluation and discharge criteria and appropriate anesthetic management and surgical techniques are followed.

Keywords: Geriatrics; Outpatient; General Surgery; Herniorrhaphy

ARAŞTIRMA

CORRESPONDANCE

Dilek ÜNAL

Dışkapı Yıldırım Beyazıt Training and Research

Hospital, Department of Anesthesiology and

Reanimation, Ankara, Turkey

Phone: 03125962553

e-mail: dilek.yazicioglu@hotmail.com

Received: 08/12/2017

Accepted: 16/03/2018

Dışkapı Yıldırım Beyazıt Training and

Research Hospital, Department of

Anesthesiology and Reanimation,

Ankara, Turkey

Haymana State Hospital, General Surgery,

Ankara, Turkey

Ankara Hernia Center, General Surgery,

Ankara, Turkey

\section{GERIATRIK HASTALARDA GÜNÜBIRRLIK KASIK FITIĞI ONARIMININ GÜVENLIĞiNIN ARAŞTIRILMASI: GERIYE DÖNÜK KONTROLLÜ ARAŞTIRMA}

$\ddot{\mathrm{O}}_{\mathrm{z}}$

Giriş: Geriatrik hastalarda günübirlik kasık fıtığı onarımının güvenliğinin araştırılması amaçlanmıştır.

Gereç ve Yöntem:Lokal anestezi ve sedasyon altında günübirlik kasık fıtığı onarımı yapılan yaşları $\geq 65$ yıl (Grup G, $n=185$ ) olan hasta kayıtları geriye dönük olarak incelendi ve veriler, yaşları 18-64 yıl (Grup K, n=185) olan hastaların verileri ile karşılaştırıldı. Hasta seçimi, anestezi ve cerrahi bakım ve taburculuk belirli protokollere göre yapıldı. Sonuç ölçütleri, istenmeyen olayların görülme sıklığı, taburculuk süresi, taburculuk geçikmesi ve planlanmamış hastane yatışı ile yeniden hastaneye başvuru sıklığıdır.

Bulgular: Geriatri ve Kontrol gruplarının sonuçları sırasıyla, yaş: $73.2 \pm 7,1$ ve $43.9 \pm 12.3$ yıl; yüksek riskli hasta sayısı Amerikan Anestezistler Derneği sınıflaması (ASA) III ( $n=55$ [\%30] ve 5 [\%3]), ASA IV ( $\mathrm{n}=4$ [\%2] ve 1 [\%0.5); minimal sedasyon kullanılan hasta sayısı 158 ve 163 ; midazolam dozu $2.7 \pm 1.1$ ve $4.6 \pm 1.7 \mathrm{mg}$; fentanil dozu $63,4 \pm 28,6$ ve $88.1 \pm 32.4 \mu \mathrm{g}$; lidokain dozu $246.6 \pm 59,9$ ve $198,6 \pm 69,8 \mathrm{mg}$ ve bupivakain dozu $39 \pm 9.5$ ve $47.7 \pm 10,7 \mathrm{mg}$ 'dır. Taburculuk süresi Grup G ve K'da sırasıyla $102 \pm 19$ ve $91.2 \pm 22.5$ dk'dır. Gruplarda ekimoz oluşma sıklığı (Grup G'de $n=2$, Grup K'da. $n=10$ ) dışında intraoperatif ve postoperatif istenmeyen olayların gelişme sıklığı ve taburculuk gecikmesi, planlanmayan hastane yatışı ve yeniden hastaneye başvuru sıklığı bakımından fark yoktur.

Sonuç: Geriatrik hasta grubunda, lokal anestezi ve sedasyon altında yapılan günübirlik kasık fıtığı onarımı, protokol bazlı preoperatif değerlendirme ve taburculuk kuralları ve uygun anestezik ve cerrahi bakım uygulanmak koşulu ile genç hastalardaki kadar güvenlidir.

Anahtar sözcükkler: Geriatri; Günübirlik; Genel Cerrahi; Kasık fıtığı onarımı 


\section{INTRODUCTION}

Inguinal hernia is a common problem, and its prevalence increases with age. The number of elderly patients who require surgical intervention is increasing accordingly. There is an ongoing debate on the surgical treatment of asymptomatic or mildly symptomatic hernias in elderly patients. It has been shown that watchful waiting may be safe, whereas it has also been stated that the improvement of quality of life in elderly patients with minimally symptomatic inguinal hernia represents an indication for elective herniorrhapy (1-3). It has been shown that elective inguinal hernia repair carries a mortality rate in the elderly patients similar to that in the general population $(4,5)$. In addition, emergency inguinal hernia surgery is associated with remarkably higher morbidity and mortality rates than elective repairs $(6,7)$. Planned herniorrhaphy under local anesthesia seems more acceptable today even for patients older than 80 years (8).

Inguinal hernia repair is an outpatient surgery eligible procedure. The main advantages of outpatient care are decreased health costs and milder patient stress. The success of safe outpatient anesthesia depends on appropriate patient selection (3). Time to discharge as well as return hospital visits and readmission rates are measures of quality for outpatient procedures $(8,9)$. Several studies have been aimed at determining the frequency of return hospital visits and readmission, as well as associated adverse events, after outpatient surgery to describe the predictors $(8,10,11)$. The higher incidence of comorbid diseases and concurrent use of medications and physiological changes in the geriatric patient population may increase the risk of anesthesia and surgery $(12,13)$. However, to date, the anesthesia and surgical risks in the outpatient geriatric population are not well defined. In this study, we aimed to investigate the time to discharge, frequency of return hospital visits and readmission, and associated adverse events after outpatient inguinal herniorrhaphy in the elderly patients and to report on the safety of the procedure under local infiltration anesthesia (LIA) and sedation.

\section{MATERIALS AND METHOD}

Ankara Hernia Center is an outpatient surgery service. Service is specific to hernia repair and a standardized anesthesia and surgical protocol is used for all patients. All data are prospectively documented in separate sheets for each patient. A retrospective data analysis was conducted to compare a group of patients aged 65 years and older (Group G, n=185) with a random sample of patients aged 16-64 years as the control group (Group C, $n=185$ ). The participants underwent elective outpatient inguinal herniorrhaphy under LIA and intravenous sedation in the period 20052010. Ethical approval and informed patient consents were obtained.

The outpatient patient selection criteria were stable medical condition and body mass index $\leq 30 \mathrm{~kg} / \mathrm{m}^{2}$ ). The patients were first evaluated by the surgeon with a standardized questionnaire for preexisting diseases, concurrent medications, and patients who needed early preanesthetic evaluation were identified. Routine preoperative testing included complete blood count, glucose, blood urea nitrogen, prothrombin time, activated prothrombin time, international normalized ratio, electrocardiography, and chest radiography. Echocardiography, stress testing, and cardiology or pulmonology expert consultations and drug cessation were planned if needed and it was assured that the patients continued to take all their medications except for acetylsalicylic acid and clopidogrel.

\section{Anesthesia protocol}

A history was elicited during preanesthetic evaluation; all systems were reviewed; a physical examination was performed; and laboratory studies were checked. Particular attention was directed to the airway and cardiovascular systems, and patients 
were asked about exercise tolerance, unstable angina, and exacerbation of chronic bronchitis. Patients with the complaints of significant respiratory disease, unstable ischemic cardiac or cerebrovascular disease, myocardial infarction in the past 6 months, and drug-eluting stents in the past 9 months were considered not appropriate for outpatient surgery.

Premedication was not administered; intravenous prophylactic ondansetron $4 \mathrm{mg}$ was provided for all patients at moderate or high risk for postoperative nausea and vomiting (PONV) (14). All patients except those having renal insufficiency received low-molecular-weight heparin (LMWH; enoxaparin sodium $20 \mathrm{mg}$ ) subcutaneously.

During surgery, heart rate $(H R)$, blood pressure, peripheral oxygen saturation $\left(\mathrm{SpO}_{2}\right)$, and respiratory rate (RR) were monitored. An intravenous Ringer's lactate solution infusion was initiated at $10 \mathrm{~mL}$ $\mathrm{kg}^{-1}$. All patients received oxygen $2 \mathrm{~L} \mathrm{~min}^{-1}$ via a nasal cannula. Initial sedation was employed with midazolam $2 \mathrm{mg}$ followed by $1 \mathrm{\mu g} \mathrm{kg}^{-1}$ fentanyl. Propofol, midazolam, and fentanyl were used with incremental boluses as needed, and the total doses were documented. The patient's response to verbal stimuli was used as the primary sedation target. The level of sedation was recorded (minimal sedation, moderate sedation and analgesia, and deep sedation).

Respiratory depression was defined as $\mathrm{SpO}_{2}$ $\leq 94 \%$ and RR $\leq 8$ breaths $\mathrm{min}^{-1}$. Maneuvers needed to manipulate airway patency were recorded. Hypertension ( $\geq 20 \%$ increase in mean arterial pressure (MAP) in comparison with baseline values) was treated with nitroglycerin or esmolol; hypotension ( $\geq 20 \%$ decrease in MAP in comparison with baseline values) was treated with a fluid bolus and/or ephedrine 5 mg; bradycardia ( $H R \quad<50$ beats $\mathrm{min}^{-1}$ ) was treated with atropine $0.5 \mathrm{mg}$; and tachycardia ( $\geq 20 \%$ increase in HR in comparison with baseline values) was treated with esmolol.
Bupivacaine $0.5 \%$ and lidocaine $2 \%$ were used for LIA. Bupivacaine and lidocaine were diluted 1:1 with saline, and epinephrine was not used. Maximum bupivacaine (2 $\mathrm{mg} \mathrm{kg}^{-1}$ ) and lidocaine (3 $\mathrm{mg} \mathrm{kg}{ }^{-1}$ ) doses were determined for each patient for LIA. The bupivacaine dose was decreased $20 \%$ in patients with a history of heart condition. Total doses of local anesthetics were recorded at the end of the procedure.

The surgeon applied LIA by using the step-bystep infiltration (15). This technique commences with intradermal, subdermal injections of the local anesthetic solution. Subcutaneous tissues are gradually infiltrated as dissection deepens. A bolus dose of 6-8 $\mathrm{mL}$ of the local anesthetic solution is given under the external oblique aponeurosis before it is incised, and additional small doses are given at the root of the spermatic cord, the pubic corner, and the internal oblique aponeurosis lateral to the internal inguinal ring.

At the end of the procedure, patients were transferred to the postanesthesia care unit (PACU). Postoperative pain was evaluated using a 0 - to $10-\mathrm{cm}$ visual analogue scale (VAS) $(0=$ no pain, $10=$ maximum pain). Postoperative pain management consisted of naproxen sodium 5-6 $\mathrm{mg} \mathrm{kg}{ }^{-1}$ every $12 \mathrm{~h}$ or acetaminophen $500 \mathrm{mg}$ every 4 to $6 \mathrm{~h}$, when the patient was able to consume oral fluids.

Patients were discharged from the center when their Modified Post Anesthetic Discharge Scoring System (MPADSS) score was $\geq 9$, and they were tolerating oral intake (16). The discharge time (time elapsed from the time the patient entered the PACU to the time to discharge from the hernia center) was recorded, and discharge time $>120$ min was considered discharge delay. Patients were contacted by telephone the day after surgery, and control visits were scheduled 1 week and 1 month later at the center. The patients were questioned for cognitive dysfunction (both hypoactive and hyperactive symptoms) and unplanned hospital visits or admissions, including other hospitals, during these contacts. 
Statistical analysis was performed with PASW Statistics for Windows version 18 software (SPSS Inc., Chicago, IL, USA). Discrete categorical data are presented as number of occurrences (n), frequencies (\%), and medians; continuous data are given as mean (SD). Student's t test, Pearson's $\chi^{2}$ test and Fisher's exact test were used as appropriate. A $p$ value of 0.05 was considered significant. Groups were compared regarding patient characteristics, anesthetic technique, type (17) and size of hernia, duration of surgery, time to discharge, discharge delay, intraoperative and postoperative adverse events, and the rate of unanticipated admission and readmission.

\section{RESULTS}

Data from 370 patients (358 men and 12 women) were analyzed (Table 1). One patient from each group was considered non-eligible for outpatient surgery because of uncontrolled heart failure (Group G) and aortic stenosis (group C).

The most common comorbid diseases were hypertension, coronary artery disease, chronic obstructive lung disease, and diabetes. In Group G, three patients had end-stage renal failure and were receiving hemodialysis, two had compensated heart failure, one had pulmonary hypertension, one had an implanted pacemaker, and three had Parkinson's disease. Three patients in Group G were on warfarin therapy, one for a history of deep venous thrombosis and two for existing atrial fibrillation. Warfarin was discontinued before surgery, and bridged with LMWH. Echocardiography was needed in four patients (2.1\%) in Group G and one $(0.5 \%)$ in Group C. Pulmonary function tests were needed in six patients (3.2\%) in Group G.

The duration of surgery was similar between groups. All patients were able to complete the procedure with the planned anesthetic technique. The majority of the patients were calm and responding to verbal commands throughout the procedure. Groups were significantly different with respect to local anesthetic consumption (Table 2). Anesthesia-related adverse events were minor, and none of them involved the airway or respiration. The hemodynamic parameters were within $20 \%$ of initial values, except in 10 patients in whom hypertension and hypotension were observed (in two and three patients, respectively, in both groups). Nitroglycerin (0.1 $\left.\mathrm{\mu g} \mathrm{kg}^{-1} \mathrm{~h}^{-1}\right)$ or esmolol $\left(0.5-0.1 \mathrm{\mu g} \mathrm{kg}^{-1} \mathrm{~h}^{-1}\right)$ infusions were used in the hypertensive patients, and the hypotensive patients received additional intravenous fluid. The mean total fluid administered was $1000 \pm 250 \mathrm{~mL}$.

Mean VAS pain scores were 0 upon arrival at the PACU and in most patients at discharge in both the groups. One patient in Group $G$ and two in Group $C$ had VAS scores $>3$ in the early postoperative period.

The mean time to discharge was longer in Group G, discharge delay was detected in 11 and 16 patients in Groups $G$ and $C$, respectively $(p<0.001, p=0.644)$. The reasons for discharge delay were transient femoral palsy $(n=1$ in both groups), dizziness ( $n=6$ in Group G vs. $n=8$ in Group C), nausea ( $n=1$ in both groups), hypotension ( $n=5$ in Group G vs. $n=8$ in Group C), and hypertension $(n=1$ in both groups). Groups were similar regarding return-hospital visit and admission rates.

The most commonly observed complications after discharge were ecchymosis and edema formation in both groups (Table 3). Cognitive dysfunction, pulmonary embolism/myocardial infarction were not observed in either of the study groups. The overall 30-day postoperative morbidity was $1.08 \%$ in patients aged 65 years and older and $0.8 \%$ in patients younger than 65 years.

Correlation analysis and multiple linear regression analysis were performed, and no apparent difference among the patient characteristics, type of sedation, and occurrence of surgical or nonsurgical adverse events was observed (Table 4). 
Table 1. Patient characteristics, duration of surgery, discharge time, discharge delay compared between groups.

\begin{tabular}{|c|c|c|c|c|c|}
\hline & & & $\begin{array}{r}\text { Group } G \\
n=185\end{array}$ & $\begin{array}{r}\text { Group C } \\
n=185\end{array}$ & $\mathrm{p}$ \\
\hline Age & & $\mathrm{yr}$ & $73.2 \pm 7.1$ & $43.9 \pm 12.3$ & $<0.001$ \\
\hline Gender & $\begin{array}{c}\text { Male } \\
\text { Female }\end{array}$ & $\mathrm{n}$ & $\begin{array}{r}179 \\
6\end{array}$ & $\begin{array}{r}179 \\
6\end{array}$ & 1.000 \\
\hline BMI & & $\mathrm{kgm}^{2}$ & $26.2 \pm 3.3$ & $26.3 \pm 3.7$ & 0.773 \\
\hline Weight & & $\mathrm{kg}$ & $73.0 \pm 11.9$ & $78.6 \pm 11.9$ & $<0.001$ \\
\hline ASA & $\begin{array}{l}\text { I } \\
\text { II } \\
\text { III } \\
\text { IV }\end{array}$ & $n$ & $\begin{array}{r}36(19.5 \%) \\
98(53 \%) \\
55(30 \%) \\
4(2 \%)\end{array}$ & $\begin{array}{r}133(71 \%) \\
41(22 \%) \\
5(3 \%) \\
1(0.5 \%)\end{array}$ & $<0.001$ \\
\hline \multicolumn{2}{|c|}{ Hypertension } & $\mathrm{n}$ & 86 & 12 & $<0.001$ \\
\hline \multicolumn{2}{|c|}{ Coronary artery disease } & $\mathrm{n}$ & 36 & 8 & $<0.001$ \\
\hline \multicolumn{2}{|c|}{ Diabetes } & $\mathrm{n}$ & 14 & - & $<0.001$ \\
\hline \multicolumn{2}{|c|}{ Chronic obstructive lung disease } & $n$ & 16 & 4 & 0.008 \\
\hline \multicolumn{2}{|c|}{ Benign prostate hypertrophia } & $n$ & 5 & 0 & 0.026 \\
\hline \multicolumn{2}{|c|}{ Acetylsalicylic acid } & $\mathrm{n}$ & 46 & 13 & $<0.001$ \\
\hline \multicolumn{2}{|c|}{ Clopidogrel } & $\mathrm{n}$ & 7 & 0 & 0.026 \\
\hline \multicolumn{2}{|c|}{ Duration of surgery } & $\min$ & $70.1 \pm 23.4$ & $69.4 \pm 23.3$ & 0.625 \\
\hline \multicolumn{2}{|c|}{ Discharge time } & $\min$ & $102 \pm 19$ & $91.2 \pm 22.5$ & $<0.001$ \\
\hline \multirow{2}{*}{\multicolumn{2}{|c|}{ Discharge delay }} & $\mathrm{n}$ & 11 & 16 & \\
\hline & & $\min$ & $189.2 \pm 55.4$ & $187.9 \pm 43.3$ & 0.645 \\
\hline
\end{tabular}

Values are in mean \pm standard deviation and numbers of occurrences. BMI: body mass index, ASA: American Society of Anesthesiologists status. Groups were different with respect to patient age, weight, ASA status, co morbid diseases and discharge time. 
Table 2. Anesthesia related data compared between groups.

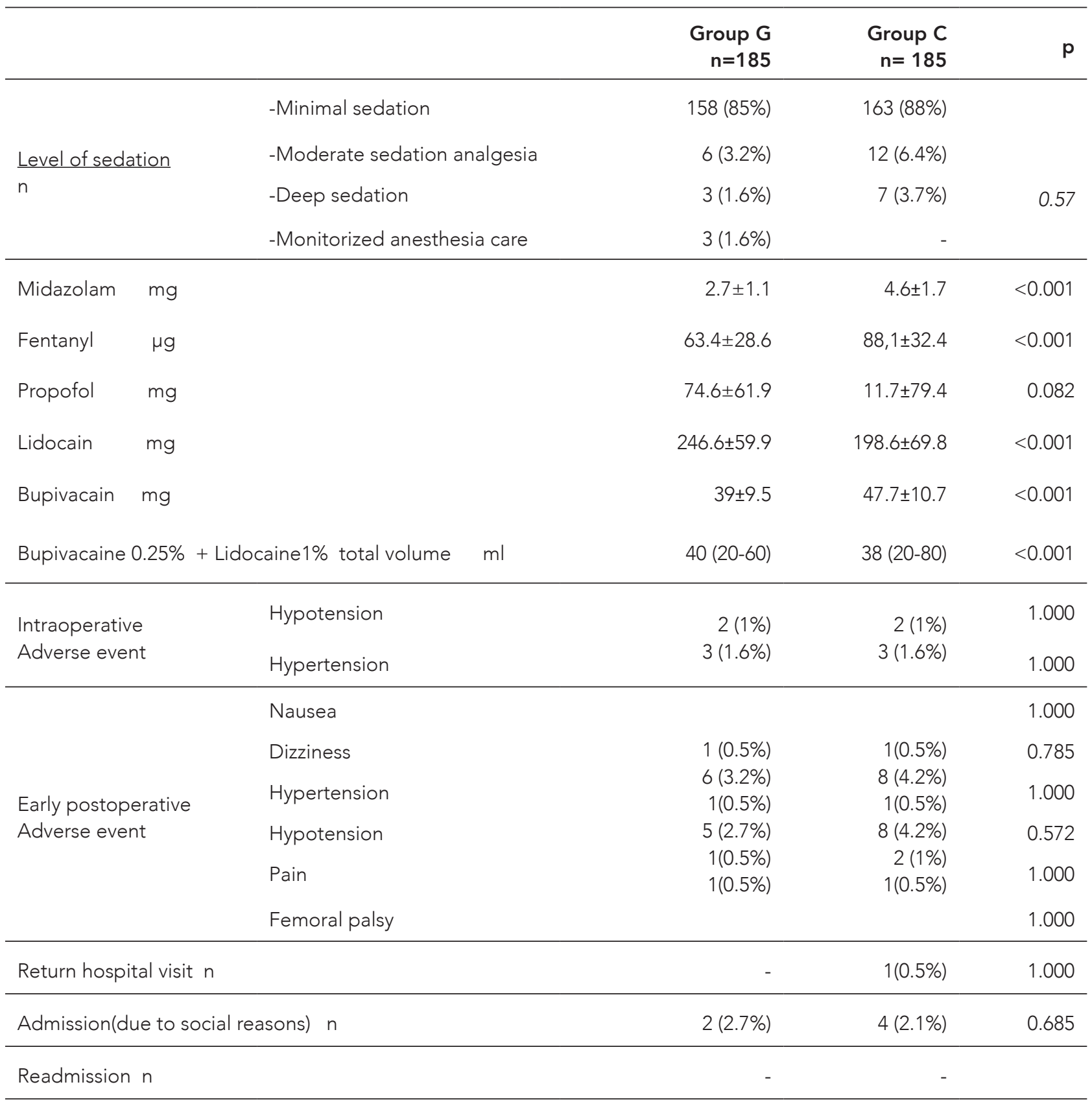

Values are in mean \pm standard deviation and numbers of occurrences and median (minimum-maximum). Groups were different with respect to midazolam, fentanyl, lidocaine and bupivacaine doses. 
Table 3. Hernia characteristics, postoperative adverse events compared between groups.

\begin{tabular}{|c|c|c|c|c|}
\hline \multicolumn{2}{|l|}{ Hernia } & $\begin{array}{r}\text { Group } G \\
n=185\end{array}$ & $\begin{array}{r}\text { Group C } \\
n=185\end{array}$ & $\mathrm{p}$ \\
\hline \multirow[t]{2}{*}{ Side $n$} & left & $82(47.7 \%)$ & $70(38.9 \%)$ & 0.112 \\
\hline & right & 89 (51.7\%) & $110(61.1 \%)$ & \\
\hline \multicolumn{2}{|l|}{ Primer/ Recurrent $\mathrm{n}$} & 157 (92\%)/ 15(8\%) & $168(90 \%) / 13(10 \%)$ & 0.736 \\
\hline \multicolumn{2}{|l|}{ Direct / Indirect $n$} & 88 (47.5\%)/ 70 (37\%) & $101(54 \%) / 69(37 \%)$ & 0.496 \\
\hline \multirow{5}{*}{ Size $n$} & Small & 15 & 35 & 0.114 \\
\hline & & 72 & 77 & \\
\hline & Medium & 45 & 49 & \\
\hline & Large & 13 & 12 & \\
\hline & Massive & & & \\
\hline \multirow[t]{7}{*}{ Type $n$} & 1 & 2 & 18 & 0.019 \\
\hline & 2 & 47 & 52 & \\
\hline & 2 & $\begin{array}{l}30 \\
53\end{array}$ & $\begin{array}{l}26 \\
51\end{array}$ & \\
\hline & 3 & 8 & 11 & \\
\hline & 4 & 18 & 15 & \\
\hline & 5 & & & \\
\hline & 6 & & & \\
\hline \multirow[t]{2}{*}{ Sac content $n$} & Omentum & 73 & 14 & $<0.001$ \\
\hline & Intestine & 26 & 77 & \\
\hline \multirow{16}{*}{$\begin{array}{l}\text { Postoperative } \\
\text { Adverse event } n\end{array}$} & Ecchymosis & 10 & 2 & 0.031 \\
\hline & & 2 & 8 & 1.000 \\
\hline & Edema & 4 & 1 & 0.113 \\
\hline & & 1 & - & 0.486 \\
\hline & Seroma & 2 & 1 & 0.614 \\
\hline & Pain & - & 2 & 0.499 \\
\hline & & 1 & - & 0.486 \\
\hline & Dyspepsia & - & 1 & 1.000 \\
\hline & & - & 1 & 1.000 \\
\hline & Wound infection & - & 2 & 0.121 \\
\hline & Hydrocel & - & 1 & 1.000 \\
\hline & 19y & & & \\
\hline & Enduration & & & \\
\hline & Plebitis-arm & & & \\
\hline & Hematoma & & & \\
\hline & Superficial fat necrosis & & & \\
\hline
\end{tabular}

Hernia recurrence $\mathrm{n}$

2

Values are in numbers of occurrences. Groups were different with respect to the type of hernia (17), sac content and the incidence of ecchymosis. 
Table 4. Multiple linear regression and correlation analysis for the total drug doses, patient- hernia characteristics, duration of surgery, discharge time; adverse events.

\begin{tabular}{|c|c|c|c|c|c|}
\hline & & Midazolam & Fentayl & Lidocaine & Buivacaine \\
\hline \multirow[t]{2}{*}{ Age } & Control & $\begin{array}{l}\text { High dose } \\
\qquad \begin{array}{r}B=0.842 \\
p=0.036\end{array}\end{array}$ & & & \\
\hline & Geriatric & & & $\begin{array}{r}\text { High dose } \\
B=34.56, p=0.000\end{array}$ & $\begin{array}{r}\text { Low dose } \\
B=8.55, p=0.000\end{array}$ \\
\hline Weight & & $\begin{array}{r}\text { High dose } \\
B=0.037 p=0.012\end{array}$ & & & \\
\hline $\begin{array}{l}\text { Adverse event } \\
\text { hypertension }\end{array}$ & Intraoperative & $\begin{array}{r}B=-0.037 \\
P=0.014\end{array}$ & & $\begin{array}{r}\text { High dose } \\
B=28.191, \quad p=0.001\end{array}$ & \\
\hline $\begin{array}{l}\text { Duration } \\
\text { of surgery }\end{array}$ & & & & $\begin{array}{r}\text { High dose } \\
r=0.246 p<0.001\end{array}$ & \\
\hline Discharge time & & & & $\begin{array}{r}\text { High dose } \\
B=0.079, p=0.005\end{array}$ & \\
\hline \multicolumn{6}{|l|}{ Sac content } \\
\hline & Intestine & $\begin{array}{l}\text { High dose } \\
\qquad p=0.000\end{array}$ & High dose $p=0.000$ & High dose $p=0.000$ & $\begin{array}{r}\text { High dose } \\
p=0.079\end{array}$ \\
\hline \multicolumn{6}{|l|}{ Type of hernia } \\
\hline & Type 1 & & & Low dose $p<0.001$ & \\
\hline \multirow[t]{2}{*}{ Size of hernia } & Massive & $\begin{array}{l}\text { High dose } \\
p=0.023\end{array}$ & High dose $p=0.009$ & & \\
\hline & Small & & & Low dose $p=0.006$ & \\
\hline
\end{tabular}

$r=$ correlation; $B=$ multiple linear regression.

\section{DISCUSSION}

The safety of elective inguinal herniorrhapy in hospitalized elderly patients was previously demonstrated (4). The present study was carried out on an outpatient basis, and the results showed that inguinal herniorrhaphy under LIA and sedation in the elderly patients is safe in the.

The rates of return-to-hospital visits after outpatient surgery range from $0.1 \%$ to $5.9 \%$ in diverse age groups and surgical procedures $(8-11,14,18)$. The safety of outpatient procedures was studied in a case mix group of 57,709 patients; the main reasons for readmission were hematoma, infection, and thromboembolic events (19). Gastroenterology and gynecology are the surgical specialties with the highest risk for return-hospital visits, and female sex is also a risk factor, whereas age is not (5). Another study of outpatient surgery demonstrated that pain and infection were the most common reasons for 
return-hospital visits, followed by fatigue and PONV, and the most common reasons for readmission were bleeding and infection (18). This study included 3532 outpatient surgery procedures. Among them, 373 (5.6\%) were inguinal herniorrhapy, and local anesthesia was used in 33\%, return hospital visits or readmission rates for herniorrhapy were not reported (18).

Postoperative morbidity was investigated in 229,033 elective herniorrhaphies. The overall incidence of readmission, length of stay exceeding 2 days, and postoperative death within 30 days was $7.1 \%(20)$. The rate of surgical complications was $3.5 \%$, and the rate of nonsurgical complications was $3.4 \%$ in these cases. The complication rate increased with age $(4.5 \%$ in patients aged $\geq 65$ years vs. $2.7 \%$ in patients aged $<65$ years), and complications were more frequent after regional anesthesia. The most frequently observed surgical complications were hematoma, wound infection, pain, and seroma, and the most frequent medical complications were pneumonia, thrombosis, and myocardial infarction. Morbidity was the lowest with LIA. This study included in-hospital both open and laparoscopic herniorrhaphies (20).

In the present study, adverse events were minor and rare. The most frequently observed adverse events were hypotension and hypertension intraoperatively and hypotension and dizziness in the early postoperative period. Serious adverse events such as myocardial infarction or pulmonary embolism were not observed. There was no unanticipated overnight stay for medical reasons, and only one patient in Group C needed to return to the center.

We consider that meticulous preoperative patient evaluation and management are the key factors of these outcomes. The anesthesiologist must evaluate every patient before surgery; however, an evaluation several days before surgery is necessary only for patients with American Society of Anesthesiologists physical status classification
(ASA) III and IV. Our patient selection criteria were in accordance with the current recommendations of the guidelines of the American Heart Association and the American College of Cardiology (21). As expected, the number of high-risk patients was higher in Group G. ASA III and IV are not per se contraindications for outpatient surgery (18). There was one patient with an implanted cardiac pacemaker. This patient's cardiologist and the manufacturer of the device were contacted. The device was evaluated before surgery and was reprogrammed to an asynchronous pacing mode; the rate-adaptive function was disabled; a bipolar electrocautery system was used. We suggest that a wider range of routine screening tests is unnecessary for outpatient inguinal herniorrhaphy and that further testing should be based on the symptoms and physical examination. The need for expert consultation is rare. We consider that patient selection should be based on the specific medical condition of each patient rather than on the presence of comorbidities and ASA physical status classification.

Our results show a statistical difference between study groups regarding discharge time. We consider this 11-min difference clinically insignificant. Pain is the most common reason for discharge delay and unplanned admission after surgery. LIA provides better pain relief after inguinal herniorrhaphy than spinal anesthesia and general anesthesia $(18,19,22)$. In our center, LIA and sedation is used as the main method. Most of our patients were pain-free in the early postoperative period, and this fact might have contributed to early discharge time. Along with effective pain control, early mobilization and oral intake may have contributed to the fact that our patients did not experience cognitive dysfunction.

We used prophylaxis for PONV only in patients at risk (14). The use of volatile agents, nitrous oxide, neostigmine, and opioids is considered an anesthesia-related risk factor for PONV, for which our patients were provided only fentanyl. It appears that fentanyl up to $100 \mu \mathrm{g}$ does not 
increase PONV incidence in patients undergoing outpatient repairs.

We consider discharge according to protocol important for low adverse event and readmission rate. A MPADSS score $\geq 9$ was used for discharge, because inguinal herniorrhaphy is a high-risk surgery for urinary retention. It was assured that the patients were able to walk without assistance and were able to consume oral food in order to prevent falls and malnutrition.

Our results indicate some differences between the groups that need interpretation regarding the doses of drugs. We decreased the bupivacaine doses in patients with a history of heart condition, and surgical anesthesia was provided by relatively increasing the lidocaine dose; this may have created bias between the study groups. The presence of a massive hernia may have increased the difficulty and duration of surgery, resulting in the patients requiring more lidocaine and midazolam, and consequently discharge time was longer in patients who had massive hernias. The higher midazolam doses in Group C can be explained by the difference in the mean weight of the groups. The

\section{REFERENCES}

1. INCA Trialists Collaboration. Operation compared with watchful waiting in elderly male inguinal hernia patients: a review and data analysis. J Am Coll Surg 2011;212(2):251-9. (PMID:21183367).

2. Patti R, Aiello P, Caruso AM, Cudia B, Di Vita G. The improvement of quality of life a indication for elective surgery in elderly patients with minimally symptomatic inguinal hernia. Ann Ital Chir 2014;85(2):136-42. (PMID:24901813).

3. Aktimur R, Çetinkünar S, Yıldırım K, et al. Comparison of the outcomes of wachfull waiting and surgery in 80 years of age and older comorbid and minimally symptomatic inguinal hernia patients. Turkish Journal of Geriatrics 2014;17(4):338-44.

4. Kulacoglu HI, Polat A, Moran M, Gök R, Coşkun F. Elective inguinal hernia repair in the elderly. TurkishJournal of Geriatrics 2000;3(2):64-8. higher fentanyl use in patients with the intestinal loop as the sac content indicates that these patients may feel more pain during the manipulation of the peritoneum.

The elderly patients are a rapidly growing group, and more geriatric patients with co morbidities will present for outpatient surgery in the future. Discharge delay as well as unplanned hospital visits or admissions can cause significant financial burden for outpatient surgical centers; thus, an evaluation of predictors of these outcomes should have an important impact on daily practice (9).

In conclusion, this study demonstrates that outpatient inguinal herniorrhaphy under LIA and sedation in the geriatric age group is as safe and feasible as in the nongeriatric patient population. It also shows that the rates of discharge delay or unanticipated admission and return hospital visits are very low, provided that meticulous preoperative evaluation, appropriate anesthetic management, and appropriate surgical techniques are used and that patients are discharged according to a discharge protocol.

5. Wu JJ, Baldwin BC, Goldwater E, Counihan TC. Should we perform elective inguinal hernia repair in the elderly? Hernia 2017;21(1):51-7. (PMID:27438793).

6. Kulah B, Duzgun AP, Moran M, Kulacoglu IH, Ozmen MM, Coskun F. Emergency hernia repairs in elderly patients. Am J Surg 2001;182(5):455-9. (PMID:11754850).

7. Işı RG, Yazıcı P, Demir U, et al. Approach to inguinal hernia in high-risk geriatric patients: Should it be elective or emergent? Turkish Journal of Trauma and Emergency Surgery 2017;23(2):122-7. (PMID:28467578).

8. Engbaek J, Bartholdy J, Hjortso NC. Return hospital visits and morbidity within 60 days after day surgery: a retrospective study of 18,736 day surgical procedures. Acta Anaesthesiol Scand 2006;50(8):911-9. (PMID:16923084). 
9. Coley KC, Williams BA, DaPos SV, Chen C, Smith RB. Retrospective evaluation of unanticipated admissions and readmissions after same day surgery and associated costs. J Clin Anesth 2002;14(5):34953. (PMID:12208439).

10. Twersky R, Fishman D, Homel P. What happens after discharge? Return hospital visits after ambulatory surgery. Anesth Analg 1997;84(2):319-24. (PMID:9024021).

11. Garcea G, Majid I, Pattenden CJ, Sutton CD, Neal CP, Berry DP. Predictive factors for unanticipated admission following day case surgery. J Eval Clin Pract 2008;14(1):175-7. (PMID:18211667).

12. Pelavski AD, De Miguel M, Alcaraz Garcia-Tejedor G, et al. Mortality, Geriatric, and Nongeriatric Surgical Risk Factors Among the Eldest Old: A Prospective Observational Study. Anesth Analg 2017;125(4):13291336. (PMID:28786844).

13. Rana MV, Bonasera LK, Bordelon GJ. Pharmacologic Considerations of Anesthetic Agents in Geriatric Patients. Anesthesiol Clin 2017;35(2):259-271. (PMID:28526147).

14. Gupta A. Evidence-based medicine in day surgery. Curr Opin Anaesthesiol 2007;20(6):520-5. (PMID:17989543).

15. Amid PK, Shulman AG. Local anesthesia for inguinal hernia repair step-by-step procedure. Lichtenstein IL. Ann Surg 1994;220(6):735-7. (PMID:7986138).

16. Palumbo P, Tellan G, Perotti $B$, Pacilè MA, Vietri F, Illuminati G. Modified PADSS (Post Anaesthetic Discharge Scoring System) for monitoring outpatients discharge. Ann Ital Chir 2013;84(6):6615. (PMID:23165318).
17. Mattila K, Hynynen M; Intensium Consortium Study Group. Day surgery in Finland: a prospective cohort study of 14 day-surgery units. Acta Anaesthesiol Scand 2009;53(4):455-63. (PMID:19239413).

18. Majholm B, Engbæk J, Bartholdy J, et al. Is day surgery safe? A Danish multicentre study of morbidity after 57,709 day surgery procedures. Acta Anaesthesiol Scand 2012;56(3):323-31. (PMID:22335277).

19. Bay-Nielsen M, Kehlet $H$. Anaesthesia and postoperative morbidity after elective groin hernia repair: a nation-wide study. Acta Anaesthesiol Scand 2008;52(2):169-74. (PMID:17999709).

20. Fleisher LA, Kirsten E, Fleischmann AD, et al. 2014 ACC/AHA Guideline on Perioperative Cardiovascular Evaluation and Management of Patients Undergoing Noncardiac Surgery. A Report of the American College of Cardiology/American Heart Association Task Force on Practice Guidelines. Journal of the American College of Cardiology 2014;64(22):e77-137. (PMID:25091544).

21. Yazicioglu D, Akkaya T, Kulacoglu H. Addition of lidocaine to bupivacaine for spinal anaesthesia compared with bupivacaine spinal anaesthesia and local infiltration anaesthesia. Acta Anaesthesiol Scand 2013; 57:1313-20. (PMID:239805580).

22. Ahonen J. Day surgery and thromboembolic complications: time for structured assessment and prophylaxis. Curr Opin Anaesthesiol 2007;20(6):5359. (PMID:17989546). 